\title{
Study on Microstructure Characteristics of Clay Rock of Xigeda Formation in Xichang City Based on Softening Test and Image Recognition
}

\author{
Zheng YANG ${ }^{\text {a, } 1}$, Ning GUO ${ }^{\text {a }}$ and Heng ZHANG $^{\text {a }}$ \\ ${ }^{a}$ College of Water and Civil Engineering, Xichang University, Xichang, Sichuan, \\ 615000, China
}

\begin{abstract}
Based on the Xigeda clay rock exposed in the back mountain of Nanshan Villa in Xichang City, the microstructure changes of Xigeda clay rock before and after water softening were studied by scanning electron microscope and image recognition of PCAS software. The results show that: (1) the clay rock of Xigeda group has flake and layered micro structural characteristics, and the surface of aggregates in natural state has honeycomb characteristics. After water softening, the aggregate particles decompose, the average size of particles becomes smaller, the honeycomb characteristics disappear, and the surface contours of particles become smooth and round. (2) With the increase of water saturation time, the number of aggregate particles and pores increases, the porosity decreases in advance and increases in the later stage. (3) Micro structural changes of the clay rock in Xigeda formation have two stages, in the first stage, the aggregates decompose and the produced fine granular clays fill the original pores, resulting in the decrease of porosity.In the second stage, the fine clay particles further soften, decompose and lose in the water, the porosity increases suddenly.
\end{abstract}

Keywords. Xigeda group formation, clay rock, microstructure, image recognition, softening test

\section{Introduction}

Clay rock of Xigeda formation is mainly distributed in Panzhihua and Xichang areas in southwest Sichuan Province [1], and is the iconic stratum of late Cenozoic in Panxi area. This set of stratum is a kind of semi-diagenetic rock deposited in river and lake facies. It has high sensitivity to water, hard when dry, rapid disintegration in water, and almost complete loss of strength. It is like rock and not completely like rock, like soil and not completely like soil, prone to landslides. In the $1960 \mathrm{~s}$, due to ignoring the particularity of the stratum, many geological hazards were induced in the construction of large-scale projects such as Chengkun Railway in Panxi area. In order to understand the causes and characteristics of the formation, many scholars began to study the clay rock of Xigeda formation. With the construction and improvement of the traffic

\footnotetext{
${ }^{1}$ Zheng Yang, College of Water and Civil Engineering, Xichang University, Xichang, Sichuan, 615000, China; E-mail: yzsd1989@yeah.com.
} 
network in Southwest China, this stratum is paid more and more attention in the engineering construction.

The stratigraphic study of Xigeda Formation started in 1938 when Chang Longqing conducted geological survey in Panxi area [1]. By means of X ray diffraction and scanning electron microscope, the composition and structure characteristics of Xigeda clay in Dukou area were studied by Peng Shengen in 1980s [2]. Wang Sijing collected the data of cohesive force and angle of internal friction of Xigeda clay rock in Panzhihua area [3]. Huang Jun studied the microscopic properties of Xigeda Formation [4]. Zhou Yunjin's research found that Xigeda stratum in Xinmin Township of Yanbian has high water sensitivity [5]. Teng Yanguo determined the geochemical characteristics of soil trace elements in Xigeda formation in Panzhihua region [6]. Through the laboratory geotechnical test of clay rock of Xigeda formation in Panzhihua New Steel $\mathrm{V}$-Ti Base, Yangbi analyzed the related physical properties from the aspects of particle analysis, mineral chemical composition and microstructure [7]. Zhang Jiaming obtained some mechanical parameters of clay of Xichang Xigeda formation under different consolidation conditions [8]. Xu Zemin gave details on the problems needing attention in the stratigraphic research of Xigeda Formation [9]. Zhang Wei studied the hydraulic properties of Xigeda clay rock in Xichang city and analyzed the influence of moisture content on shear strength of clay rock [10-11]. Taking the slope of Sichuan Jiangtong Rare Earth Industrial Park as an example, Liao Hengyun studied the creep characteristics of Xigeda clay rock [12]. Wang Zhijie deeply studied the deformation characteristics of Tongzilin tunnel excavation in Xigeda Formation [13]. Du Yuxiang studied the Xigeda formation in Zhaizi village, Jinsha River and found that the strength and deformation changes of Xigeda formation through the tri-axial compression test [14].

\section{Distribution of Xigeda Stratum}

The Xigeda formation forms between the Neogene and the Quaternary Pleistocene (4.2 $\sim 1$ Ma) [15-16]. The Xigeda formation is widely distributed in Sichuan Province, especially in Panxi area, mainly in strip or flake form, with an area of $21 \times 10^{4} \mathrm{~km}^{2}$ (figure 1). The Xigeda stratum in Liangshan state is mainly distributed in Xichang City, Mianning County and Dechang County along the Anning Valley.The stratum is mainly composed of pale yellow (figure 2a), gray-black (figure $2 b$ ), pale yellow and grayblack interbedded (figure 2c) clay rock. With obvious horizontal layered structure, it is typical of lake phase deposition.

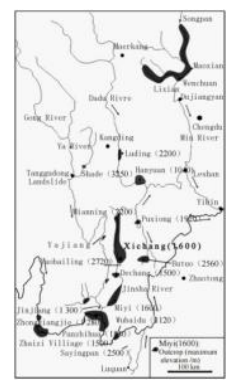

Figure 1. Distribution of Xigeda stratum [17]. 


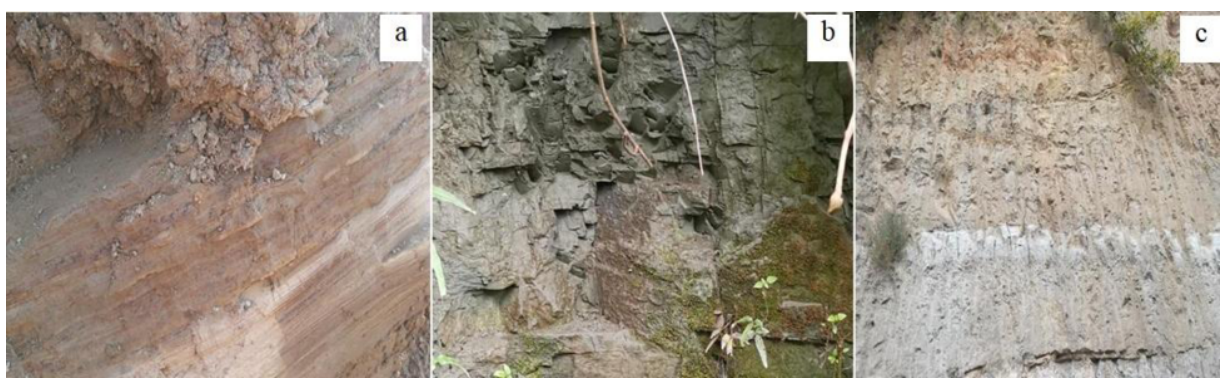

Figure 2. Xigeda clay rock. Note: a) the back hill of Xichang Nanshan Villa, b) Dechang, c) Mianning.

\section{Study on Softening Test and Microstructure Characteristics of Clay Rock}

\subsection{Basic Physical Indicators}

The samples are collected in the deep of $2 \mathrm{~m}$ from the back hill of Nanshan Villa, Xichang City, and the average natural moisture content was $22.76 \%$ and the average natural density was $1.78 \mathrm{~g} / \mathrm{cm}^{3}$. The clay rock samples consist mainly of clay minerals and quartz, the clay composition is mainly illite, and less of kaolinite and chlorite.

\subsection{Study on Microstructure Characteristics Based on Softening Test}

In order to understand the microstructure characteristics of clay rock after saturated softening, this paper designs 1 group of reference sample, 2 groups of test samples. Direct drying of clay rock sample is reference sample. One group of test samples was dried after 60 days water softening test, the other group was dried after 180 days water softening test. Three groups of dried samples were amplified 2000 times under TM3000 electron microscope, as shown in figure 3.

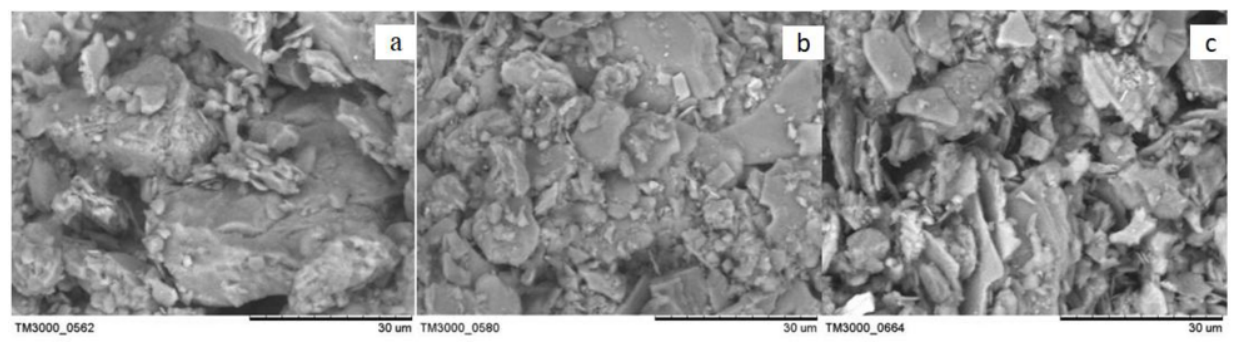

Figure 3. Micro structure of Xigeda clay rock. Note: a) natural state dry sample, b) dry after 60d saturated, c) dry after $180 \mathrm{~d}$ saturated.

Figure $3 \mathrm{a}$ is the dry sample of the natural state, aggregate particles sizes are at $25 \sim$ $45 \mu \mathrm{m}$. They have the characteristics of lamellar, and the surfaces of particles have the characteristic of honeycomb. There are larger pores between larger aggregates and filled by less small particles. Figure $3 \mathrm{~b}$ shows drying sample saturated after 60 days with aggregate particles size of $15 \sim 25 \mu \mathrm{m}$. They also have the characteristics of lamellar. A large number of small particles are deposited on the surface of aggregates, and the pores are obviously smaller than those in figure 3a.It is assumed that the aggregate particles decompose after saturated softening and some new formed small 
particles fill in the pores. Figure 3c shows drying sample saturated after 180 days, the overall structure becomes loose, the average size of particles decreases significantly, and the aggregate particles sizes are at $5 \sim 20 \mu \mathrm{m}$. They have the characteristics of lamellar. The aggregates have certain directional alignment along the layered direction. Compared with figure $3 \mathrm{a}$, the surface profiles of aggregate particles become smooth and round and the pores are obviously larger. It is inferred that after long-term saturated softening, the aggregate particles are gradually decomposed into small particles, and some new formed small particles are lost in water, resulting in further increase of porosity.

\subsection{Research on Microstructure Characteristics Based on Image Recognition}

PCAS software is a quantitative analysis software for particles and pores image recognition. The software can automatically identify all kinds of pores and particles in the image, and obtain the number, area, length, width, orientation, shape coefficient and other statistical parameters of pores and particles after binarization and vectorization [18]. For quantitative analysis of the change characteristics of particle size and pore structure before and after softening test of Xigeda clay rock, PCAS software is used to identify and statistics the image of Xigeda clay rock.

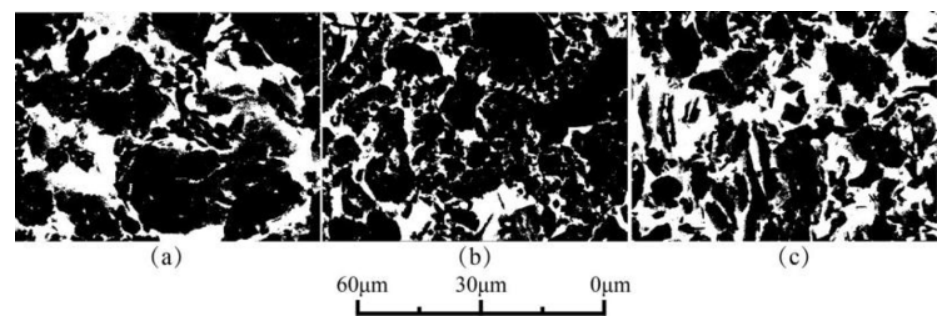

Figure 4. Micro-image recognition of Xigeda clay rock. Note: a) natural state dry sample, b) dry after $60 \mathrm{~d}$ saturated, c) dry after $180 \mathrm{~d}$ saturated.

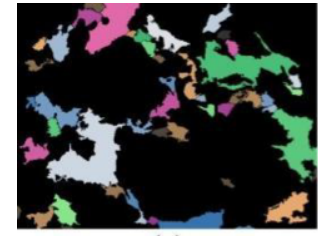

(a)

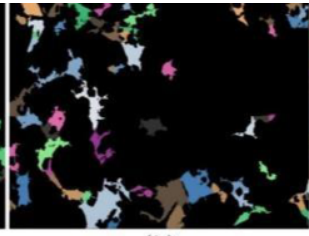

(b) $30 \mu \mathrm{m}$

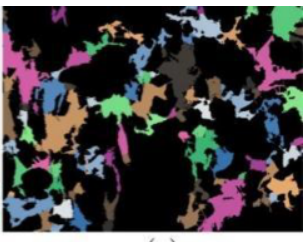

(c)

Figure 5. Pores in Xigeda clay rock. Note: a) natural state dry sample, b) dry after 60d saturated, c) dry after 180d saturated.

The figure 3 is imported into the PCAS software,after binary processing [19], figure 4 is obtained. Blacks are the identified particles and whites are the identified pores. The pores are further treated to obtain figure 5, in which blacks are the identified particles, colors are the identified pores, and different pores are distinguished by different colors. Further statistics the pixel areas and quantities of particles and pores using the automatic identification and statistical function of PCAS software. Each image has a total pixel area of $640 \times 480$.As shown in figure 6 , the number of particles, 72 , the number of pores, 52 and the porosity, $25.1 \%$ were identified in the natural state 
drying sample (dry sample after 0 day saturated). A total of 106 particles, 58 pores and $15.2 \%$ porosity were identified in the drying sample after 60 days saturated. After 180 days saturated, drying sample is identified 123 particles, 88 pores and porosity of $33.5 \%$. The number of cluster particles and pores continuously increase as saturated time increases. The number of particles of $60 \mathrm{~d}$ saturated sample increase $47.2 \%$ compared with natural sample and pores increase $11.5 \%$. The number of particles of $180 \mathrm{~d}$ saturated sample increase $16.0 \%$ compared with $60 \mathrm{~d}$ saturated sample and pores increase $51.7 \%$.Compared with natural samples, the porosity of $60 \mathrm{~d}$ saturated sample decrease by $39.4 \%$ in advance. With the increase of saturation time, the porosity of $180 \mathrm{~d}$ saturated sample increase by $120.4 \%$ compared with $60 \mathrm{~d}$ saturated samples. This is due to the decomposition of clay rock in water. It is speculated that in the first stage, the decomposed fine clay particles fill the original pores, resulting in the decrease of porosity. In the later stage, the fine clay particles further soften and decompose, and lose in water, resulting in a sudden increase of porosity.

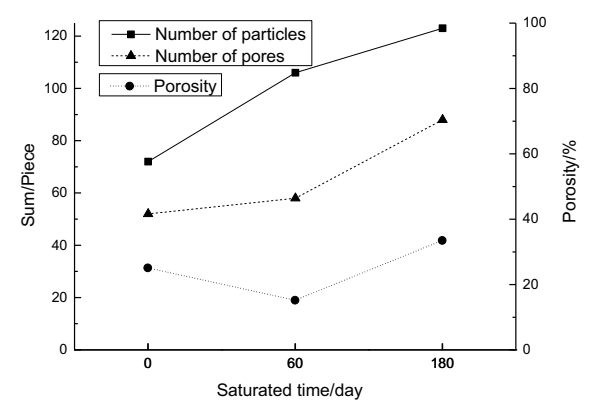

Figure 6. Relationship between number of particles and pores, porosity, and days of water saturation.

\section{Conclusion}

In this paper, scanning electron microscopy (SEM) and image recognition methods were used to study the microstructural characteristics of the Xigeda clay rock exposed in the back mountain of Nanshan Villa in Xichang City after water softening. The following conclusions were obtained:

(1) The results of electron microscopy shows that the Xigeda clay rock has lamellar and layered characteristics, the surfaces of natural dry aggregates have honeycomb characteristics, the average size of particles is relatively large, and the aggregate particles decompose with the increase of saturation time, the average size of particles becomes smaller, and the particle surface profiles become smooth and round. (2) Image recognition and statistical analysis of particles and pores in electron microscope images were carried out by PCAS software. It is found that with the increase of water saturation time, the number of aggregate particles and pores increase, the porosity decreases in advance and increases in the later stage.(3) The decomposition of Xigda clay rock saturated in water has two stages: the fine clay particles decomposed in the first stage fill the original pores, resulting in the decrease of porosity, and the fine clay particles further soften, decompose and lose in the water, resulting in the sudden increase of porosity.(4) The stability in water of the Xigda clay rock is very important for engineering. In this paper, the microstructural characteristics of the Xigda clay rock after water softening are studied. However, the effect of water 
softening on the reduction of rock mass strength should be studied by combined mechanical test.

\section{Acknowledgements}

This project was supported by Natural Science Research Project of Sichuan Education Department (18ZB0546), Key R \& D Project of Sichuan Science and Technology Plan (2018GZ0499). Author: Zheng Yang, male, major in civil engineering and geology engineering teaching and scientific research.

\section{References}

[1] Liu HJ, Nie DX. The overview of the Xigeda strata's study. Advance in Earth Sciences. 2004 Jun; 19(S1): 80-82.

[2] Peng SE. Study on the engineering geological characteristics of clay in Xigeda formation. Hydrogeology \& Engineering Geology. 1986 Feb; (2): 16-18.

[3] Wang SJ, Huang DC. Environmental geology in Panxi Area. Beijing: Ocean Press;.Aug 1990.

[4] Huang J. Study on microstructure of Xigeda formation. Chengdu: Chengdu University of Technology; Jun 1992.

[5] Zhou YJ, Zeng LM. Analysis of formation characteristics of slope deformation in secondary pumping station of Honggeti Water Project. Design of Hydroelectric Power Station. 2000 Jun; (02): 61-65.

[6] Teng YG. Baseline study on soil environment geochemistry in Panzhihua Area. Chengdu: Chengdu University of Technology;Apr 2001.

[7] Yang B, Fan GZ, Liu WL, Xu LD. Engineering property of Xigeda strata of panzhihua new steel V-TI base. Science Technology and Engineering. 2010 Feb; 10(04): 973-976.

[8] Zhang JM, Liu WL, Xu ZM, Li QK. Experimental research on dynamic characteristics of Xigeda formation claystone in Xichang. Journal of Earthquake Engineering and Engineering Vibration. 2012 Feb; 32(01): 154-160.

[9] $\mathrm{Xu} \mathrm{ZM,} \mathrm{Liu} \mathrm{WL.} \mathrm{Some} \mathrm{problems} \mathrm{in} \mathrm{the} \mathrm{study} \mathrm{of} \mathrm{the} \mathrm{genesis} \mathrm{of} \mathrm{Xigeda} \mathrm{Formation.} \mathrm{Earth} \mathrm{Science}$ Frontiers. $2011 \mathrm{Sept}$; 18(05): 256-270.

[10] Zhang W. The research of water physical and mechanical properties's of Xigeda clay rocks. Kunming:Kunming University of Science and Technology; Oct 2011.

[11] Zhang W, Xu ZM, Liu WL, Li L. Study on the influence of water content to shear strength of Xigedastrata clay rock in Xichang Geotechnical Investigation \& Surveying. 2011 May; 39(05): 1-5.

[12] Liao HY. Experimental study on creep characteristics of Xigeda' clay rock and its slope creep analysis-A case analysis of a slope in industrial park of Sichuan Jiang Tong. Chengdu: Chengdu University of Technology; Jun 2016.

[13] Wang ZJ, Xu RN, He NF. Study of deformation characteristics of large cross-section tunnel. Tunnel Construction. 2016 Dec; 36(12): 1412-1420.

[14] Du YX, Sheng Q, Wang S, Fu XD, Luo HX, Tian M, Wang LW, Mei HR. Study of microstructure and mechanical properties of semi-diagenetic rock of Xigeda Formation. Rock and Soil Mechanics. 2020 Apr; 41(04): 1247-1258.

[15] Qian F, Xu SJ, Chen FB, Zhao YT. Study on magnetic formation of Xigeda. Mountain Research. 1984 Dec; (04): 275-282.

[16] Luo YL, Liu DS. Study on sedimentary environment evolution and cyclic stratigraphy of Xigeda formation. Quaternary Sciences. 1998 Nov; (04): 373.

[17] $\mathrm{Xu} \mathrm{ZM}$, Liu WL, Huang RQ. Engineering geological characteristics of Zhaizicun giant ancient landslide along Jinsha river and its occurrence mechanisms. Chinese Journal of Rock Mechanics and Engineering. 2011 Sept; 30(S2): 3539-3550.

[18] Liu C, Shi B, Zhou J, Tang CS. Quantification and characterization of microporosity by image processing, geometric measurement and statistical methods: Application on SEM images of clay materials. Applied Clay Science. 2011 Jul; 54(1) 97-106.

[19] Liu C, Xu Q, Shi B, Gu YF. Digital image recognition method of rock particle and pore system and its application. Chinese Journal of Geotechnical Engineering. 2018 May; 40(5): 925-931. 